Acrodystrophic Neuropathy

By John D. Spillane and Charles C. Wells. Pp vii +109 , illustrated. London: Oxford University Press, 1969. £2 10s.

The central content of this monograph is a report of the clinical and radiological features in sixteen patients with peripheral sensory loss, trophic ulceration and osteolytic lesions in the extremities. In addition, there is an extensive historical review of previous interpretations of this syndrome. Semantics and nosology are discussed at some length, the authors advocating the term 'acrodystrophic neuropathy' to describe the clinical picture without implying any specific aetiology. It could perhaps be argued that a combination of biochemical, electrophysiological and morphological advances might allow a more precise classification of hereditary neuropathies in the future.

The topic is a difficult one and any relevant new information is worth recording. The clinical photographs and X-rays will prove useful to those who have not seen many cases of 'acrodystrophic neuropathy'.

The Human Nervous System-A Developmental Approach

By R. L. Holmes, J. A. Sharp and M. D. Brown. Pp. 136, illustrated. London: J. \& A. Churchill, 1969. £2 10s.

This book from the University Department of Anatomy at Leeds presents the teaching of neuroanatomy from the background of the embryonic development of the CNS. It is directed to the medical student prior to his involvement in clinical neurology. The text is complemented by most elegant and clear diagrams and electron micrographs, illustrating the development and structure of the spinal cord and brain. Included are elementary discussions of neurophysiology and neuropathology and an attempt is made to relate symptoms and signs with specific regional damage. These sections could with advantage be enlarged, attempted brevity occasionally leading to difficulties, 'involuntary muscular contractions' being described as resulting from lesions of the pallidum or substantia nigra: phrases such as'corticobulbar and corticospinal types of movements'-need clarification. Space should perhaps be given to a discussion of the cerebral vasculature, lesions of which lend themselves to an anatomical treatment.

These minor criticisms apart, the book succeeds ably in its chosen task of explaining, clarifying, and teaching the structure of the adult human nervous system. A most welcome feature is the brief discussion of brain organisation in a number of animal species, which should lead the biology student to appreciate the complexity of the human organisation, without confusion by bewildering detail. This book will aid the teaching of neuroanatomy and help the student achieve insight into brain structure.

\section{Studies in Neurology}

By Sir Charles Symonds. Pp. vi +344 , illustrated. London: Oxford University Press, 1970. $£ 4$.

Sir Charles Symonds has not been a prolific writer, but many of his papers are gems and have rightly become neurological classics. This book, to mark his eightieth birthday, collects together some of his more important publications, ranging over the whole of his professional life. They are preceded by a brief but fascinating autobiographical introduction. Sir Charles has been the doyen of bedside clinical neurology in Britain, and these papers reflect his particular expertise.

The papers are grouped together under seven topic headings: vascular accidents; epileptic and other seizures; head injuries; psychological disorders; and, finally, papers on miscellaneous subjects. A number of the earlier papers are largely of historical interest; others among his more recent publications are still fully relevant to present clinical practice' His articles on 'A particular form of headache' (migrainous neuralgia) and 'Cough headache' are models of clinical description.

This is a book to be read for interest and enjoyment as well as for information.

\section{Progress in Neurology and Psychiatry Vol. 24}

Edited by E. A. SPIEgel M.D. Pp. 541. London: William Heinemann Medical Books, 1969. $£ 11$ 3s.

This should be a standard reference book in clinical and research libraries. The measure of the volume's success is the reviewers' ability to correlate advances in the various disciplines of neurology and psychiatry, putting into perspective over 4000 publications. The majority of papers discussed come from 1967 and 1968 and in some subjects in which rapid advances have been made, progress has outstepped this book. Thus in the treatment of Parkinson's disease by aromatic amines only preliminary reference to the work of Cotzias and his group can be given; in the discussion of Creutzfeld-Jacob disease, preliminary transmission experiments of 1968 are quoted, but more recent confirmatory work is not available. However, such minor criticisms are unavoidable in a work of this nature which succeeds in particular noteworthy reviews of neuro-pharmacology, pathology, epilepsy; together with various aspects of psychology. The editor has been faced with the problem of selection and is leaving electroencephalography, cerebral trauma, vascular disorders-amongst other subjects-to be discussed in the next volume. Considerable overproduction of medical literature is responsible for this difficulty, but in a book attempting and achieving remarkably complete reviews, the clinical neurologist and psychiatrist might welcome separate volumes for each discipline, although such a division would be artificial and hinder rather than help cross-fertilization of ideas. The student and research worker consulting this guide will be led with clarity to what is important and the clinician can review advances bordering upon his territory. The volume should be available for reference in all active neurological and psychiatric centres. 